Western University

Scholarship@Western

Department of Economics Research Reports

Economics Working Papers Archive

1970

\title{
Money Supply and Money Demand: An Econometric Analysis for Canada
}

Thomas J. Courchene

Alex K. Kelly

Follow this and additional works at: https://ir.lib.uwo.ca/economicsresrpt

Part of the Economics Commons

Citation of this paper:

Courchene, Thomas J., Alex K. Kelly. "Money Supply and Money Demand: An Econometric Analysis for Canada." Department of Economics Research Reports, 7009. London, ON: Department of Economics, University of Western Ontario (1970). 
RESEARCH REPORT 7009

MONEY SUPPLY AND MONEY DEMAND:

AN ECONOMETRIC ANALYSİS FOR CANADA

by

Thomas J. Courchene
and
Alex. K. Kelly,

April, 1970

*

It is a pleasure to acknowledge the research assistance rendered by Gordon Davies and Karen Sharp as well as the comments by J. R. Zecher. We also express our appreciation to the Bank of Canada and especially Peter Miles for answering our numerous requests for data. Earlier versions of this paper were read to the annual meetings of the Canadian Economics Association (June, 1968), to Chicago's Money Workshop, to Harvard's Canadian Policy Seminar, and to the University of Western Ontario Money Workshop. The paper was completed while Courchene, the senior author, was a post-doctoral fellow at the University of Chicago. Much of the work in the paper was supported by a Canada Council grant. The authors are at the University of Western Ontario and the University of Saskatchewan, respectively. 


\section{Introduction}

Money income, $Y$, can be expressed as a product of a money stock, $M$, and a money velocity, $v$. In turn the money stock can be expressed as a product of a monetary base, B, and a money supply multiplier, m. Combining these yields the quantity-theory-type expression $Y=v m B$. Interpreted as an identity, this equation automatically yields a value for $v m$ once $Y$ and $B$ are specified. With the money supply defined as the monetary base, m equals unity and the product $\mathrm{mv}(=\mathrm{v})$ is simply the income velocity of the monetary base. With a more extended definition of money the money supply multiplier assumes a value greater than unity but velocity declines proportionally, since the product mv is constant for given $B$ and $Y$. This simple but broadly encompassing equation provides the framework within which this paper proceeds. Specifically, we intend a) to investigate the determinants of money supply, $\mathrm{mB}$, and money demand, $\mathrm{v}$, and $\mathrm{b}$ ) to investigate the interaction among $\mathrm{m}, \mathrm{v}$, and B. For example, taking logarithms of $\mathrm{Y}=\mathrm{vmB}$, differentiating, and dividing through $\mathrm{d} \log \mathrm{v}$ yields $\frac{\mathrm{d} \log \mathrm{Y}}{\mathrm{d} \log \mathrm{v}}=1+$ $\frac{d \log m}{d \log v}+\frac{d \log B}{d \log v}$. The elasticity of money income with respect to velocity, $\epsilon(Y, v)$ will equal unity only if $\frac{d \log m}{d \log v}$ and $\frac{d \log B}{d \log v}$ are zero. Questions such as whether or not $m$ and $B$ are in fact independent of velocity are precisely the types of issues we intend to address in this paper.

Rather than focussing directly on the behavior of $\mathrm{m}$ and $\mathrm{v}$, we investigate the determinants of and interaction between the money supply multiplier and the velocity of money within the context of an econometric model. In addition our focus on the determinants of the supply of money goes beyond the money supply multiplier: the systematic determinants of the monetary base are also investigated. Throughout the paper emphasis is directed more toward money supply than money demand. Indeed, the money-supply-multiplier approach provides the framework through which we analyze money demand. 
The outline of the paper is as follows. Part II derives a money-supplymultiplier formulation and in the process defines empirical counterparts for such variables as the monetary base and the supply of money as well as familiarizes the non-Canadian reader with some aspects of "Canadiana." Part III contains the heart of the empirical analysis--a 26-equation model of the Canadian economy with emphasis on the interaction among the Bank of Canada, the chartered banks, and the non-bank public. In Part IV, we derive impact, dynamic and steady state multipliers as we manipulate the results of the model to yield implications for money demand, money supply, the interaction between $\mathrm{m}, \mathrm{v}$, and $\mathrm{B}$, and the temporal behavior of the proximate determinants of the money supply. The concluding section draws further implications and lends perspective to some of our findings.

\section{Derivation and Properties of the Money Supply Multiplier}

For the period with which we are concerned (1955-1965) chartered banks were required to hold reserves of $8 \%$ against the item termed "Canadian dollar deposit liabilities" (henceforth referred to as $D)^{1}$. This item is defined as the sum of demand deposits (gross of float, i.e., items in transit) Dd, personal savings deposits Ds, corporate notice deposits Dn (actually called "non-personal term and notice deposits"), and federal government deposits, Dg. The definition of the money supply that we adopt for this paper is the sum of currency outside

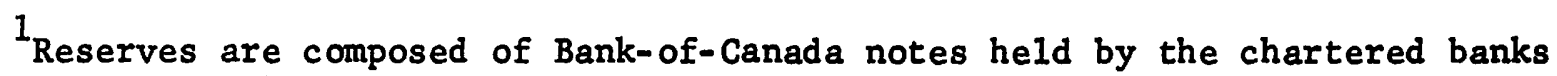
and deposits with the Bank of Canada. The basis for the monthly reserve calculation (called the "statutory basis") is as follows: Bank-of-Canada notes and $D$ are calculated as averages of the 4 consecutive Wednesdays ending with the second last Wednesday of the previous month; deposits with the Bank of Canada are defined as the average over the banking days of the current month. Coin in bank vaults does not qualify as reserves presumably because it is not a liability of the Bank of Canada. 
banks $C$, plus the first three components of $D, i_{. e .}{ }^{2}$

$$
M=C+D d+D s+D n .
$$

The monetary base is the sum of reserves, $R$, plus currency outside banks:

$$
B=R+C
$$

Since our hypothesis is that each component of the money supply exhibits behavior different from that of the other components we desire a formulation of the money supply multiplier that will allow for the public's preference for the different types of money. Toward this end we express the components of $M$ as fractions of demand deposits, i.e.,

$$
c=\frac{C}{D d} ; \quad(I I .4) \quad s=\frac{D s}{D d} ;(I I .5) \quad n=\frac{D n}{D d}
$$

where $c, s$, and $n$ are, respectively, the ratios of currency, personal savings deposits, and corporate notice deposits to demand deposits. In addition, let $r$ represent the actual reserve-deposit ratio of the banking system, i.e.,

$$
\mathbf{r}=\frac{\mathrm{R}}{\mathrm{D}}
$$

where the denominator is Canadian-dollar deposit liabilities.

Substituting II.3-II.6 into II.I and II.2 yields

$$
M=\operatorname{Dd}(1+c+s+n) \text {, and }
$$

$$
B=D d(r+c+r s+r n)+r D g \text {. }
$$

2 This differs from the accepted Canadian definition in two ways. First, we include float as part of the money supply. In part this is required because in its published statistics the Bank of Canada does not indicate the amounts of each type of deposit in transit and when they present money supply figures net of float, all the float is deducted from demand deposits. To follow this procedure might seriously. bias the demand-deposit series. Furthermore our empirical investigation suggests that "kiting" is an economic variable: demand deposits gross of float are considerably more interest sensitive than Dd net of float. Secondly, $C$ does not include coin outside the banks.: This is an arbitrary decision on our part but it is consistent with coin being excluded from reserves. Note also that both Ds and Dn are interest-bearing deposits, the former being held only be persons and the latter by corporations and charitable institutions. Unlike its U.S. counterpart, Ds carries chequing privileges. And except for that portion of Dn which are "fixed-term" deposits (although growing rapidly of late, they accounted for only $1 \%$ of all savings deposits, $1 . e$. , of $\mathrm{Dn}$ and $\mathrm{Ds}$, in 1962) corporate notice deposits are also chequable. Finally demand deposits include, in addition to the traditional "current accounts", personal chequing accounts, deposits of provincial governments and deposits of other banks (mostly foreign banks). 
Combining II. 7 and II.8, we obtain

$$
M=\left(\frac{1+c+s+n}{r+c+r s+r n}\right)(B-r D g) ; \quad \text { or } M=m B^{\prime}
$$

where $m$ is the money supply multiplier and $B^{\prime}$ is the monetary base adjusted for reserves held against government deposits. ${ }^{3}$ our treatment of $B^{\prime}$ may be somewhat unfamiliar. Brunner and Meltzer [2, p. 32] follow a somewhat different procedure. Rather than adjust the base for reserves held against government deposits, they introduce the ratio $\mathrm{r} \frac{\mathrm{Dg}}{\mathrm{Dd}}$ into the denominator of their multiplier formulation. For a given level of $M$, therefore, the Brunner-Meltzer formulation would yield a larger monetary base and a smaller multiplier than would II.9. Since we shall assume that the reserve ratio is constant, ${ }^{4}$ these formulations are equivalent from an economic stand point.

The derivatives of $m$ with respect to $c$ and $r$ are negative while those with respect to $s$ and $n$ are positive. ${ }^{5}$ The corresponding elasticities of $m$ with respect to $c, r, s$, and $n$ (calculated at sample means) are $-.53,-.36,+.30,+.037$. Direct estimation of these elasticities using a log-1inear equation yields virtually identical values: $-.524,-.351, .292$ and .038 . The average values on an end-of-last-month-in-quarter basis for 1955.3-1965.4 for c, r, s, n, and $m$ are, respectively, $.3749, .0741,1.6168, .1944$ and 5.468 . These values for 1965.4 are $.3391, .0752,1.6123, .3572$ and 5.6846 . The multiplier has been increasing over

3 The parametric composition of II. 9 is similar to that derived by Lindbeck [11, Ch. 6].

4 While the reserve ratio has been falling somewhat over our sample period 1955.3 to 1965.4, the variation in the ratio is exceedingly small. For example, from 1963 to 1965 the monthly ratios, on a statutory basis, varied between .0807 and .0814 .

5 The derivatives for $c, r, s$, and $n$ are, respectively, $[(r-1)(1+s+n) / J]$, $[-(1+c+s+n)(1+t+n) / J],[c(I-r) / J]$, and $[c(1-r) / J]$ where $J$ is the square of the denominator of the multiplier. The reason why the derivatives of $s$ and $n$ are positive is that a switch from demand deposits to Dn or Ds will increase the multiplier because we have assumed the currency drain to be against Dd only. 
the sample period primarily because of the sharp rise in the ratio of corporate notice deposits to $\mathrm{Dd}$ (or what amounts to the same thing, since the same $r$ applies to all bank deposits, a fall in the ratio of currency outside banks to bank money, i.e., to $\mathrm{Dd}+\mathrm{Dn}+\mathrm{Ds})$. Values for 1965.4 for the components of $M$ are given in Table III below. 6

We now turn to the econometric model. Rather than estimate the behavior of $s, n, c$, and $m$ directly, we specify and estimate equations for the variables that comprise these ratios, i.e., Dd, Ds, Dn, C, and $R$. This allows us to investigate the determinants of the demand for money and, after reforming the ratios, the supply of money as well.

\section{An Econometric Model of the Canadian Economy} with Emphas is on the Monetary Sector

\section{A. The Model: An Overview}

The model of the Canadian economy is presented below. An alphabetized listing of the variable definitions appear in Appendix A. The twenty-six endogenous variables are enumerated immediately below the model. All data are seasonally unadjusted and all value variables are in millions of current dollars. All flow variables are at quarterly rates. Unless otherwise indicated, data for non-flow variables are the month-end values for the last month of each quarter. The time span of the estimation is from the third quarter of 1955 to the fourth quarter of $1965 .^{7}$ The model is estimated via two-stage least squares. Bracketed numbers beneath the regression coefficients are "t-values". The multiple-

${ }^{6}$ A comprehensive graphical and numerical analysis of the behavior over this period of the "proximate determinants" has been deleted from the final version of this paper. It is available upon request. Alternatively, see [10].

7 Month-end data were selected because corporate notice deposits, Dn, are available for the sample period only in this form. 
correlation coefficient, $\bar{R}$, has been corrected for degrees of freedom.

The model is divided into three parts: the monetary sector; the term

structure of interest rates; and the real sector. We do not make any further reference to the real sector in the text; it is included so that the monetary sector may have some interaction with the real sector and to obtain a set of exogenous variables to facilitate the two-stage estimation procedure. However, since some of these equations draw heavily upon specifications developed by other researchers we use Appendix B to acknowledge our debt.

Our view of the behavior of the monetary sector, incorporated in the model, Is highly simplified. Equation III.1 is the public's demand for currency, C. The banks are assumed to accommodate fully this demand (equation III.6). Equation III.5 depicts the central bank's supply of the monetary base, $B$, to the economy. The difference between the supply of the monetary base and the stock of currency outside banks yields the supply of reserves (equation III.7). Banks are assumed to accept passively this level of reserves (equation III.13).8 Equations III.2, III.3, and III.4 are respectively, the demand equations for demand deposits, Dd, personal savings deposits, Ds, and non-personal term and notice deposits, Dn.

8 This implies that we do not allow for a "discount window" in our model. And this is as it should be; for only 2 of the 48 month-ends from 1962-1965 did the chartered banks borrow from the Bank of Canada and both these amounts were less than $1 / 2$ of $1 \%$ of reserves. It is possible to argue, like Fand and Tower [5], that the purchase and resale agreements between the money-market dealers and the Bank of Canada should be included as part of chartered-bank borrowings. But this borrowing too is infrequent; for the same 48 month-ends the dealers were in debt to the Bank on only six occasions. More importantly, however, it is not clear that the dealer borrowings need imply that the banks are in need of reserves nor do they need imply that the monetary base increases by the amount of the borrowing. Take the $\$ 99$ million borrowing on December 30, 1964 (by far the largest borrowing in the 48-month period). Chartered banks did not need additional reserves (their reserve ratio for December was the highest in two years). Day loans from the chartered banks to the dealers were near average. Furthermore, the Central Bank appears to have altered government deposits to prevent these dealer borrowings from increasing the monetary base. 

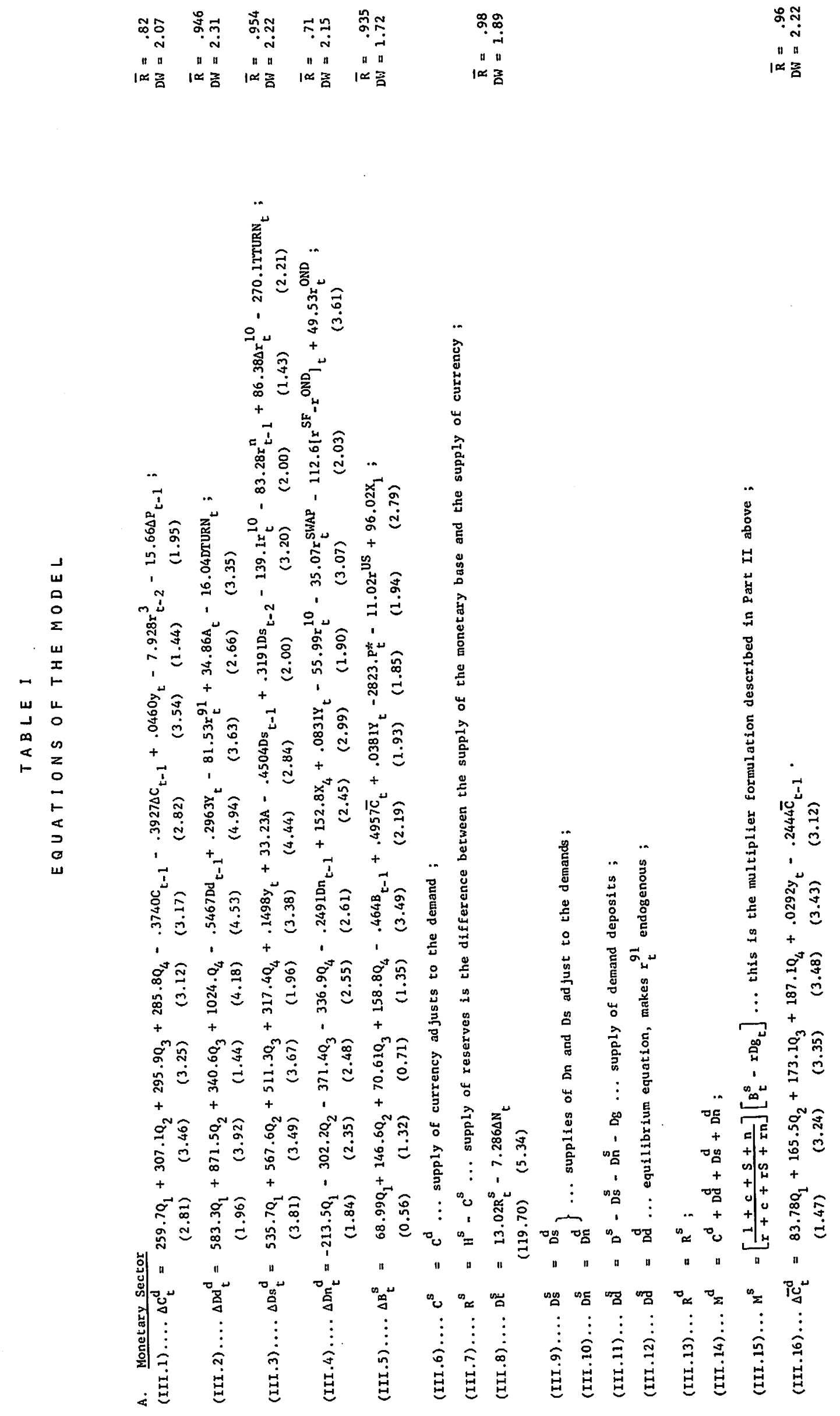

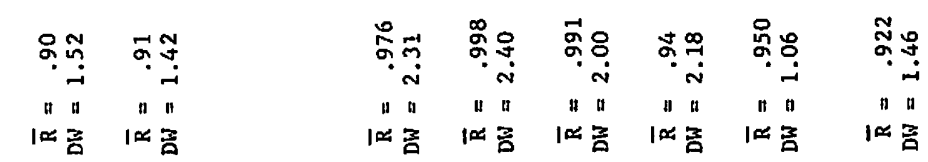

ஸับ

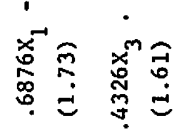

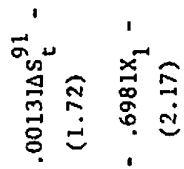

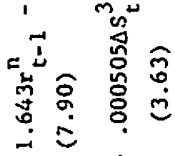

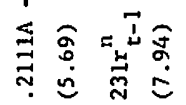

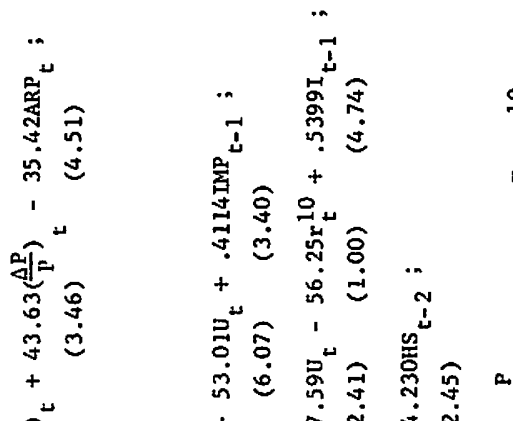

竞

$\overbrace{}^{i}$

尊

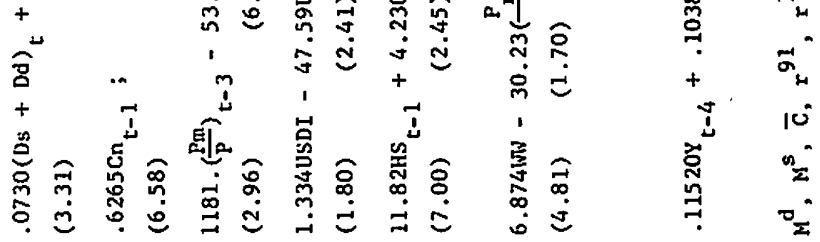

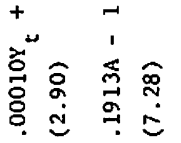

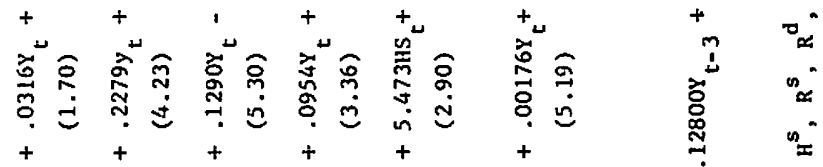

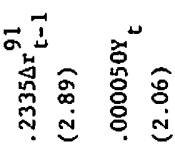

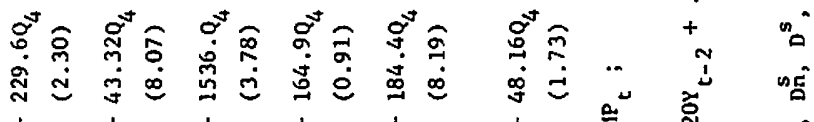

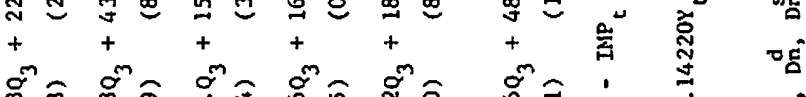

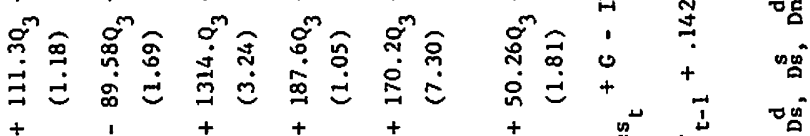

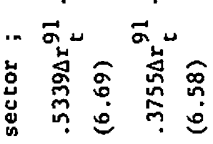

+

它

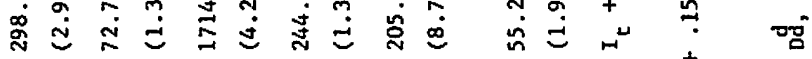

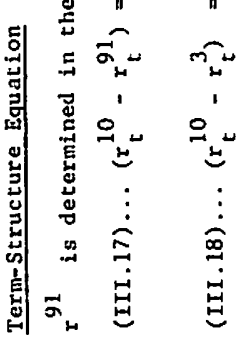

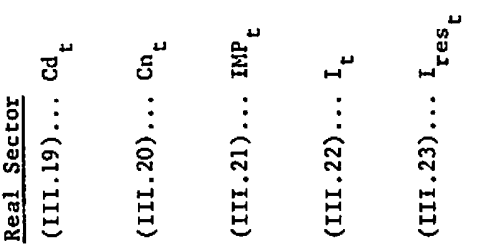

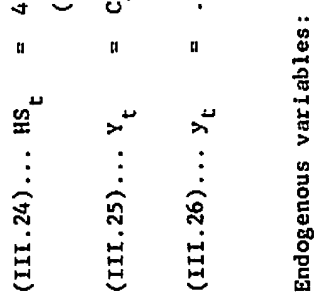


The sum of these three demands plus federal government deposits, Dg, must equal $\mathrm{D}^{s}$. There are several ways in which this condition can be satisfied. The method we adopt is to assume that the chartered banks meet, at existing rates, all demands for personal savings deposits and for corporate notice deposits (equations III.9 and III.10). 9 Demand deposits are assumed to bear the brunt of any required adjustment. Accordingly, III.11 is the chartered banks supply of demand deposits. Equation III.12 is an equilibrium condition: the demand for demand deposits must equal the supply of demand deposits. Within the context of the model, this equation "determines" the treasury bill rate $-\mathrm{r}^{91}$ adjusts so that $\mathrm{D}_{\mathrm{d}}^{\mathrm{d}}$ equals $\mathrm{D}_{\mathrm{d}}^{\mathrm{s}}$. Equation III.14 is the demand for money--a summation of the component demands. The supply of money is given by the money supply multiplier formulation embodied in III.15. ${ }^{10}$ As it turns out, equation III.15 is not absolutely essential to make the model complete. It can be jettisoned and in its place one can set $\mathrm{M}^{\mathrm{s}}$ equal to $C^{s}+D^{s}+D s^{s}+D^{s}$. We prefer the former specification given the basic framework of our analysis. The reader is asked to ignore equation III.16 for the time being.

Since the treasury-bill rate, $r^{91}$, is determined in the monetary sector, we need only to determine $r^{3}$ and $r^{10}$ in the term-structure equations. ${ }^{11}$ Equation III. 17 determines the long-term rate $\mathrm{r}^{10}$ while III. 18 determines the three-year rate, $r^{3}$. Several definitions and identities complete the model.

${ }^{9}$ This is quite similar to the approach adopted by Goldfeld [6, pp. 25-26]. ${ }^{10}$ We could have introduced $c, s$, and $n$ explicitly into the model by adding the section II equations for these variables. This would have added only to the quantity and not to the quality of the model.

${ }^{11}$ Again we adopt the Goldfeld approach [6, p. 134]. 
B. The Model: A Brief Look at the Equations ${ }^{12}$

The Demand For Currency

The current literature is somewhat ambiguous on the question of whether currency is related more to transactions (current income, $Y$, for our purposes) or wealth (permanent income, y). 13 our findings suggest that the demand for currency in Canada is related more closely to permanent income: hence the inclusion of $y$ in equation III.1. Variables $Q_{1}$ to $Q_{4}$ are the seasonal intercepts. The two additional varlables in the equation represent our attempt to replicate some aspects of the Goldfeld specification [6, p. 133]. If prices are expected to rise the public will demand less currency: hence a negative coefficient for $\Delta \mathrm{P}_{t-1}$. The appearance of the lagged three-year interest rate,. $\mathrm{r}_{t-2}^{3}$ is the result of considerable experimentation with various rates. That its coefficient is not statistically significant suggests that currency demand in Canada is not very interest sensitive.

The Demand For Demand Deposits

In line with recent Canadian work [12], [8] we hypothesize that demand deposits are held primarily for transactions purposes. Accordingly, the Dd equation in the model (equation III.2) embodies current rather than permanent income and the treasury bill rate rather than a long-term rate. But there is also a portfolio rationale for holding demand deposits and the average maturity

${ }^{12}$ With few exceptions, we discuss only those specifications which appear in the model. An earlier draft presented alternative specifications for several of the equations. These results are available upon request.

13 For example, Heller [7] finds that the sum of currency and demand deposits is related to current income while time deposits are related more to permanent income, thus implying that currency demand is a transactions demand. Yet Cagan suggests that "currency in circulation exceeds amount needed for retail transactions, and apparently serves also as a store of value" [4, p. 281]. 
term, $A_{t}$, captures, in part, this motive. ${ }^{14}$ Finally, equation III.2 contains an additional variable, DTURN, the turnover ratio of demand deposits (i.e., the debits to demand deposits divided by the average level of demand deposits). From a value of 36.1 in January, 1955, this ratio (at annual rates) increased to 96.9 by September, 1965. We interpret this variable to be a proxy for "technical change" in demand deposits, irrespective of whether this technical change is in the form of things like more efficient clearing arrangements or in the increased desire on the part of the public to make more efficient use of demand deposits. (The chartered banks' efforts to increase the attractiveness of corporate notice deposits after 1961 and hence to create a close substitute for Dd may have contributed significantly to the increase in DTURN.) As the turnover ratio of demand deposits increases, the demand for Dd should fall ceteris paribus: hence the negative coefficient for DTURN in equation III.2. Equation III.2 indicates that $55 \%$ of the desired change in Dd occurs in the first quarter, implying a rather quick adjustment to equilibrium.

The Demand For Personal Savings Deposits

Personal savings deposits, Ds, are hypothesized to be related to wealth rather than to income: hence the use of permanent income rather than current income. The average maturity of the public debt, $A_{t}$, plays a more important role (In terms of both t-values and coefficient size) in this equation than in the

${ }^{14}$ The principal reason for including $A_{t}$ in the equation is to capture the impact on demand deposits of the massive refunding of the public debt in 1958. The average term to maturity of publicly held debt increased from 8 years in June, 1968 to 14.9 years in September, 1968. The result of this operation was a sharp decrease in liquidity in the public's asset portfolios which, on the interpretation that demand deposits are held partly on wealth account, would tend to increase the demand for Dd. 
demand-deposit equation. 15 This is consistent with the notion that changes in the average maturity of the public debt should have a greater impact on balances held mostly for wealth purposes (Ds) than on balances held more for transactions purposes (Dd).

The long-term bond rate, $\mathrm{r}^{10}$, represents the opportunity cost of tying up funds in personal savings deposits. Varlables $r^{n}$ and $\Delta r^{10}$ are included to estimate the effect of expectations regarding interest rates on the demand for personal savings deposits. If current rates are above the "normal rate", then the possibility of capital gains relative to losses increases and encourages investment in instruments that afford opportunities for such gains. Personal savings deposits afford no such opportunity. Accordingly, $r^{n}$ (defined as $r^{10}$ minus an eight-quarter average of $\mathrm{r}^{10}$ ) shoüld acquire a negative coefficient-as it does in III.3. On the other hand, if interest rates are currently increasing, investors may delay investment in securities (to avoid capital losses should rates continue increasing) so that personal savings deposits become a more attractive alternative. We attempt to capture this effect by including $\Delta \mathrm{r}_{\mathrm{t}}^{10}$ in equation III.3. While the coefficient is not significant, it is correctIy signed. 16 Finally we note that the adjustment to equilibrium in III. 3 is rather lengthy.

${ }^{15}$ Even though the size of the coefficient for $A_{t}$ in III.3 is slightly smaller than it is in III.2, the lag in equation III.3 is such that the steady-state coefficient for $A_{t}$ is much larger for the personal-savings-deposit equation.

${ }^{16}$ Other researchers have opted for slightly different and in some cases more sophisticated variables than $r^{n}$ and $\Delta r_{t}^{10}$, e.g., Goldfeld [6, p. 56] and Miles [12, p. 126]. 
Equation 1 of Table II demonstrates that current income does not perform as well as permanent income as an argument in the demand function for Ds. Note that the interest rate variable in this equations is the differential between $r^{10}$ and the savings-deposit rate, $r^{S A V}$. This latter rate, by itself, did not enter any of the Ds specifications with a significant coefficient.

\section{Corporate Notice Deposits}

Averaging about 500 million dollars per year prior to 1961 , corporate notice deposits soared to over 2 billion dollars by 1965. This increase reflects the chartered banks decision in 1961 to compete more actively for surplus corporate funds. 17 These deposits are hypothesized to be positively related to income $Y_{t}$, and negatively related to the long term interest rate, $r_{t}^{10}$. The "own" rate, $r^{\text {OND }}$, enters the equation with the appropriate (positive) coefficient. This rate is defined only for the period 1961-1965. The differential between the rate of prime finance-company paper and the rate on notice deposits $\left(r^{S F}-r^{O N D}\right)$ acquires a negative coefficient--again as hypothesized since finance-company paper is a substitute for $D_{n}$. This variable too is defined only for the 1961-1965 period. The rate on swap deposits ${ }^{18}$ (available only for the 1962-1965 period) acquires a very significant negative coefficient. The downward movement in this rate near the end of our sample period also contributed to the upsurge in corporate notice deposits. Finally, equation III.4 includes variable $\mathrm{x}_{4}$, a dumny-variable intended to capture the effect ${ }^{\circ}$.

17 For more detailed analyses of the behavior of these deposits see Shearer [17, pp. 341-348], the Canadian Bankers' Association [3, p. 48] and Miles [12, ch. 5]: Our debt to Miles' work is especially great since the Dn equation borrows heavily from his specification.

${ }^{18}$ Swap deposits are foreign (primarily U.S.) deposit liabilities of the chartered banks. Banks do not have to hold reserves against these foreigncurrency deposits. The rate on swap deposits is inclusive of any gain or loss from changes in the Canadian exchange rate. We treat these deposits as a substitute for $D n$ and hence the negative coefficient for $r^{\text {SWAP }}$. 
of the failure of Atlantic Acceptance Finance Corporation in June, 1965. This failure and the accompanying uncertainty it generated led to a shift of funds from 'some non-bank intermediaries to the banking system and in particular to Dn. The Reaction Function of the Pank of Canada

To enhance understanding of the money supply process it is essential to investigate the extent to which the monetary base responds systematically to various stimuli from the private sector. 19 Equation III.5, therefore, represents our attempt to endogenize Canadian monetary policy. Even though the Bank of Canada a) maintains that it carries out a given monetary policy objective by influencing the level of chartered-bank reserves and b) emphasizes that it does not allow changes in the public!s holding of currency to interfere with the desired level of reserves, we employ the monetary base rather than bank reserves as the dependent variable in the reaction function. Since we include currency as one of the explanatory variables in the equations this is equivalent to making reserves the dependent variable if indeed there is a full and immediate offset to any changes in currency outside banks. Our use of a stockadjustment model to depict policy action seems appropriate because the Bank of Canada characterizes its policy as a "process of successive approximation" and "as working toward a certain level of cash reserves" [1, p. 148]. The coefficient of $B_{t-1}$ in III.5 indicates that approximately $50 \%$ of any desired change in policy is effected in the first quarter.

19 For a discussion of why a reaction function may be necessary from an econometric standpoint consult Goldfeld [6, pp. 188-90] and Wood [20]. The latter paper also contains many insights on some theoretical aspects of specifying reaction functions. Reaction functions have also been estimated to ascertain the implicit trade-offs of the monetary authorities among various policy targets, e.g., Reuber [14]. 
The four targets we experimented with correspond to the announced objectives of Canadian monetary policy: full-employment; price-level stability; balance-of-payments considerations and the "needs of trade". Since these objectives are correlated with each other it is not very surprising that we were unable to specify a reaction function embodying all four. Equation III.5 contains three of these targets. 20 If prices increase by more than $1 / 2$ of $1 \%$ per quarter (i.e., if $\mathrm{P}^{*}$ is positive), the Bank will decrease the monetary base in the following quarter (i.e., a negative coefficient for $\mathrm{p}_{t-1}$ ). Balance-of-payments considerations are captured by the inclusion of the U.S. Treasury bill rate, $r^{\text {us }}$ (defined only for the period during which canada was on a fixed-exchange rate). It enters the equation with the appropriate sign: an increase in $\mathbf{r}^{\text {us }}$ will cause the monetary authorities to increase the Canadian counterpart (via a decrease in the monetary base). Finally, the coefficient on income (the "needs of trade") indicates that for each dollar increase in income (at quarterly rates) the monetary base is increased by nearly 4 cents. Two of the alternate specifications for $B_{t}$ (equations 2 and 3 of Table II) incorporate an unemployment target variable, U*t, which acquires the hypothesized (positive) coefficient.

The currency variable in equation III.5 is average-of-Wednesdays currency, $\bar{c}_{t}$, rather than month-end currency $C_{t} \cdot$ Under the Canadian system for reserve calculation, fluctuations in average-of-Wednesdays currency outside banks are more relevant to reserve calculations than month-end fluctuations so it is the former than the central bank should be more concerned about. Indeed this is the case: $C_{t}$ does not acquire a significant coefficient when substituted for $\bar{c}_{t}$ in III.5. The coefficient of $\bar{c}_{t}$ indicates that in the first

${ }^{20}$ The specification for these "targets" borrows heavily from Shapiro [16]. 


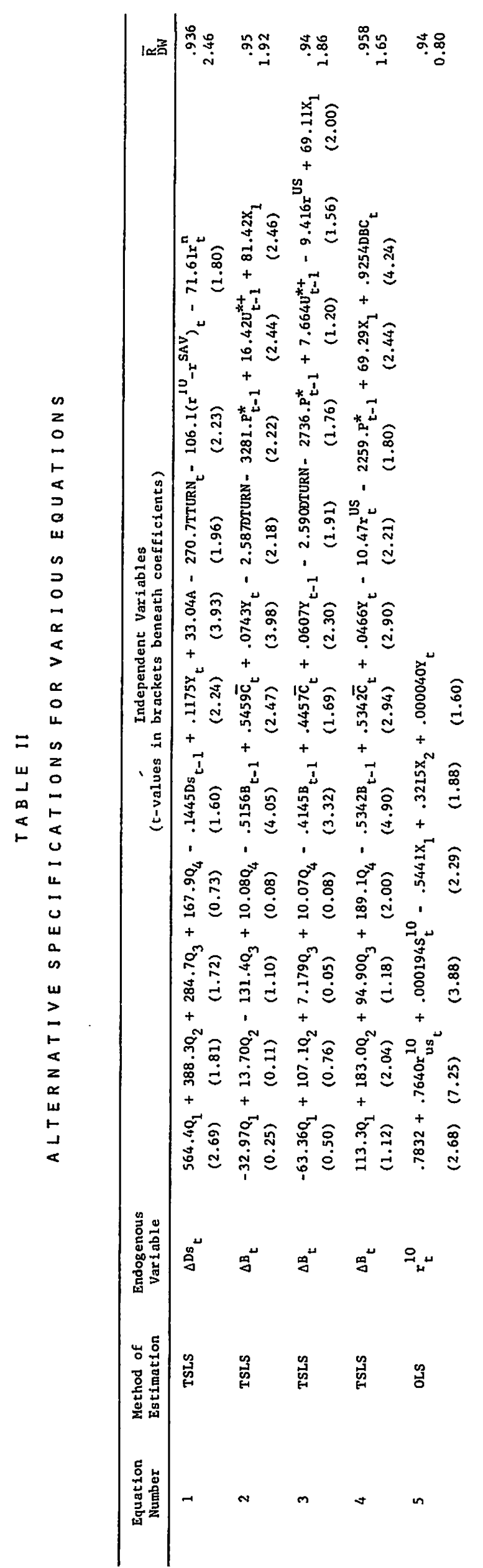


quarter the Bank of Canada offsets $50^{\not 1}$ of every dollar of currency drain. In the steady state there is full offset: the long-run coefficient for $\bar{c}_{t}$ is 1.06 (i.e., .4957 $\div$.4648). The remaining variable in III.5, i.e., $x_{1}$, is a dummy variable introduced to capture the effect on the monetary base of the decision by the Bank to support bond prices during the Conversion Loan (the 3rd quarter of 1958). The Bank effectively lost control of the hase and the shift variable $X_{1}$ indicates that the result of the bond-support policy was an increase in $B$ of 96 million dollars.

Turning to some of the alternative specifications for the base, equations 2 and 3 (Table II) include DTURN which enters with a negative coefficient: given an increase in DTURN, ceteris paribus, the base need not be as large to support the same volume of payments. Equation 3 depicts the authorities responding to income with a one-quarter lag. Equation 4 is included to test any suggestion that the use of month-end data has seriously biased the results for the base equation. Variable DBC is the difference between charteredbank month-end and average-of-Wednesdays deposits with the Bank of Canada. Since the coefficient of DBC is not different from unity this equation can be interpreted as having the average-of-Wednesday base as the dependent variable. The coefficients in equation 4 are quite similar to those in III.5 so that specifying the month-end base as the monetary policy variable does little in the way of distorting the monetary policy implications implicit in III.5. Although we adopt III.5 formulation for the model, Part IV will make use of some of the other specifications and also allow for an exogenous change in the monetary base. 21

21 The major difference between III. 5 and the base equations in Table II is that the response of $B_{t}$ to a change in $Y_{t}$ is much lower for the former. With an increase in $Y_{t}$, unemployment and prices will likely move in a manner that would call for a decrease in the base. Since these latter two policy targets are exogenous in our model we felt it appropriate to utilize the base equation embodying the smallest response to income. This is III.5. 
Since the currency variable that enters the base equation is $\bar{c}_{t}$ and not $\mathrm{C}_{t}$ and since it is important for Part IV that $\overline{\mathrm{c}}_{t}$ be endogenous, we need a separate equation for it. This is equation III.16.

The Supply of Canadian-dollar Deposits Liabilities, $D^{\mathbf{S}}$

Equation III.8 depicts $D^{S}$ as a multiple (equal to 13.02) of charteredbank reserves. This corresponds to a month-end reserve ratio of 0.77 . The other variable in III. 8 is $\Delta N_{t}$ (defined as the difference between chartered-bank month-end holdings and average-of-Wednesdays holdings of Bank of Canada notes). There is considerable variability in the level of currency held by banks at month end, much of which depends on which day of the week the month ends. Banks should react passivly to these changes since they are not relevant for reserve calculations. Hence $\Delta N_{t}$ should (and does) acquire a negative coefficient--a decrease in currency inside banks will leave chartered banks with a lower month-end reserve ratio (i.e., a higher value of $D^{s}$ for any given level of $R^{s}$ ).

\section{The Term-Structure Equations}

With $r^{91}$ determined in the monetary sector, equations III.17 and III.18 are sufficient to determine $r^{3}$ and $r^{10}$. The inclusion of the change in the treasury bill rate in the equations captures the spirit of the expectations theory of the term structure. Long-term rates are averages of expected short-term rates. Under the assumption of inelastic expectations, however, "changes in the short rate will cause smaller changes in the long rate. Hence, this will produce a negative sign." [6, p. 95, fn. 41]. Note that the larger negative coefficient for $\Delta r_{t}^{91}$ in the $r^{10} r^{91}$ equation is precisely what one would expect. The interpretation of the income variable is straightforward: an increase in income will, following standard Keynesian analysis, 
result in a rise in interest rates. But since short rates fluctuate more than long rates, a rise in income will narrow the differentials $r_{-r}^{10} 91$ and $r^{10}-r^{3}$ and the effect should be greater for the former differential. Equations III.17 and III.18 bear this out. An increase in the average maturity of the public debt, A, will increase the supply of long-term bonds and, therefore, depress bond prices and increase bond rates. This in turn will increase the long-term bond rate relative to other rates, i.e., increase the differentials. This variable is significant in both equations and, as expected, has a greater impact (in terms of the size of the coefficient) for $r^{10}-r^{91}$.

If long-term bond rates are above their normal rates, investors expect capital gains from investing in bonds. Thus the normal rate variable, $r^{n}$, should acquire a negative coefficient in both III.17 and III.18. It enters these equations with a significant negative coefficient and the larger coefficient (absolute value) for the $r^{10}-r^{91}$ equation is expected. Variables $\Delta s^{91}$ and $\Delta s^{3}$ are, respectively, the changes in the supply of Treasury bills and of government securities with less than three years to maturity. As hypothesized they acquire negative coefficients since an increase in the supply of treasury bills, for example, will decrease the price and raise the rate on Treasury bills, thus narrowing the differential.

The remaining variablesin the term structure equations are shift variables, included to capture the impact on the term structure of specific events during 1955-1965: $\mathrm{X}_{1}$, as mentioned previously, represents the Bank of Canada's support of bond prices (depressing bond rates) for the third quarter of 1958; $\mathrm{x}_{2}$, with a value of unity for the second and third quarters of 1962, isolates the impact of the "Austerity Program" on the term structure; 
$\mathrm{X}_{3}$, with a value of unity for the third quarter of 1959 , represents the failure of the Bank of Canada to put in a reserve bid for the Treasury bill auction. All enter with the expected negative sign.

One valid criticism of our term-structure equations is that they fail to recognize, in a direct way, the dependence of Canadian rates on U.S. rates. While it could be incorrect to deny that the U.S. rates have a strong influence on Canadian rates, it would be equally incorrect to suggest that Canadian variables have 1ittle impact on Canadian rates. Equation 5, Table II, illustrates this point. For example, the 1958 Conversion Loan resulted in a substantial increase in Canadian rates relative to U.S. rates (the $\mathrm{S}^{10}$ variable is the supply of outstanding bonds with more than ten years to maturity). ${ }^{22}$

IV. Some Dynamics Relations to the Canadian Monetary Sector

A. Elasticities

As a prelude to the presentation of impact multipliers, we list the first-quarter and steady-state elasticities of the monetary variables with respect to a change in current income, $\mathrm{Y}_{t}:{ }^{23} \mathrm{Dd}(.62,1.13) ; \mathrm{Ds}(.03,1.47)$; $\operatorname{Dn}(.887,3.56) ; C(.045, .68) ; M(.27,1.39) ; s(-.59, .34) ; \mathrm{n}(.26,2.43)$; $c(-.58,-.45)$; and $m(.14, .30)$. The steady-state elasticities of $s, n$ and $c$

${ }^{22}$ Since the dependent variable in equation 5 is $\mathrm{r}^{10}$ rather than a rate differential, variables $X_{2}$ and $Y_{t}$ acquire positive coefficients.

${ }^{23}$ This elasticity exercise distorts the spirit of the model considerably. In addition to treating income as if it were exogenous, we are also assuming that other endogenous variables do not change, with one exception--the money supply is assumed to accommodate the change in money demand. The reserve ratio is assumed to remain unchanged--an assumption we maintain throughout this section. 
are such that they all contribute to a rise in money multiplier, m. The first-quarter income elasticity for $s$ is negative while the steady-state elasticity is positive. This arises because the lag in Ds equation is much greater than that in the Dd equation. In both the first quarter and the steady state, then, the result of an increase in $Y$ is an Increase in the money supply multiplier. In both cases the elasticty is considerably less than unity but the steady state elasticity is double the first-quarter elasticity. Applying the technique used in the first paragraph of this paper, one can obtain the percentage change in velocity resulting from a one per cent change in income simply by deducting the income elasticity of money from unity. The short-run income elasticity of velocity, so to speak, is .73 (i.e., 1.0-.27) and the steady state value is -.39 (i.e., 1.0-1.39). Velocity exhibits considerably more variability than the money supply multiplier. These results will serve as a backdrop against which the results of the next section can be compared.

\section{B. Impact and Steady State Multipliers}

Table III contains the impact, dynamic and steady-state multipliers for various specifications of the Bank's reaction function. We refer the reader to the first two columns of the table where we present the impact of a $\$ 100$ million change in $G^{24}$ (quarterly rates) on selected endogenous variables. Values for $s, n, c, m, M$, and $v$ are derived from the appropriate endogenous variables. One of the interesting features of the impact multipliers in column 1 is that the response of the monetary authorities in

${ }^{24}$ Assume that $G$ is an increase in exports with no change in $M$ (i.e., it is sterilized). In calculating the multipliers, the reserve ratio is assumed to remain at its 1965:IV level, namely, .0762 and government deposits $\mathrm{Dg}$ are held constant. 


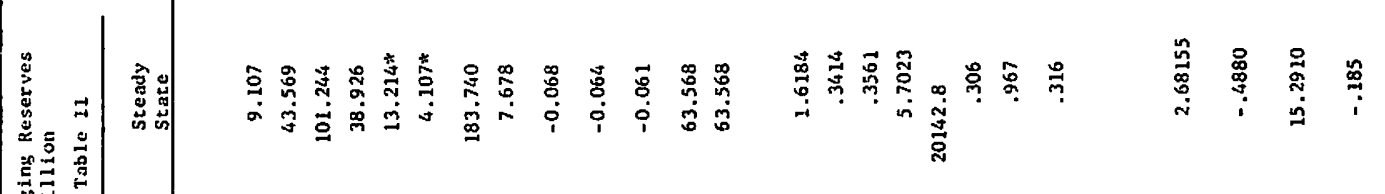

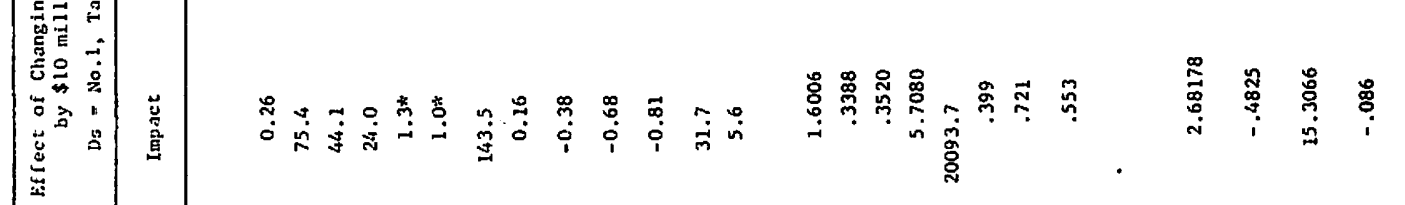

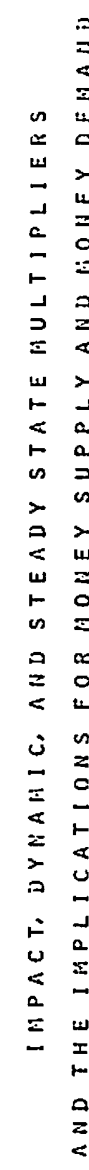

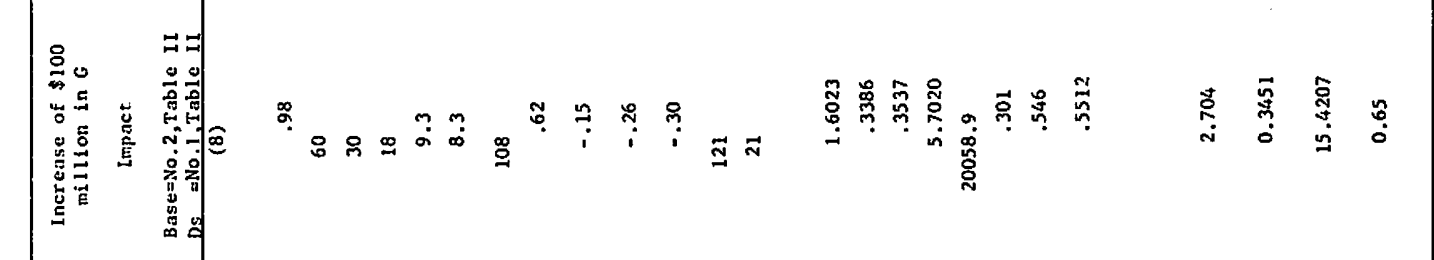

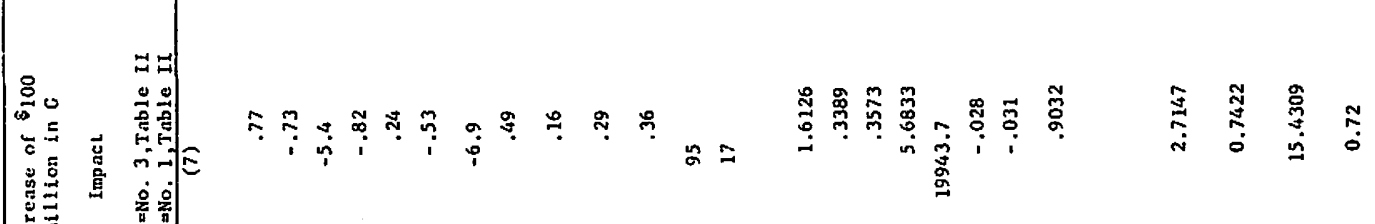

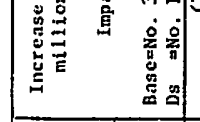

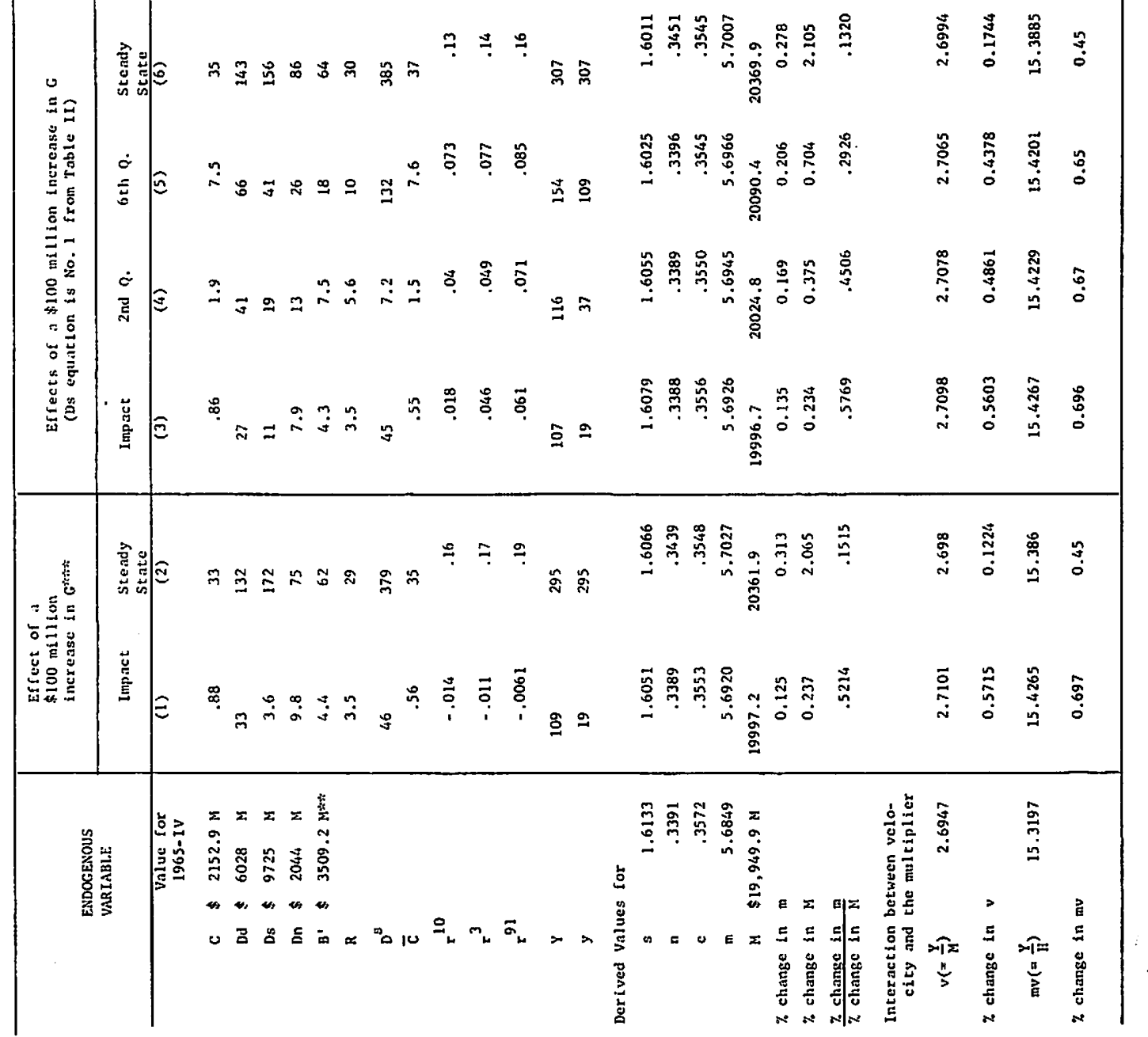


the face of an increase in $G$ generates a fall in the level of interest rates. In more familiar terms, the IM curve shifts more to the right than does the IS curve. The equilibrium response, column 2, is the more traditional one: an increase in $G$ increases interest rates. One reason for these results is that the impact increase in Ds, i.e., $\$ 3.6$ million, is extremely small relative to the steady-state response. This is due to the long lag in the Ds equation. At unchanged interest rates, the change in $G$ leaves the increased demand for money short of the increased supply. To clear the market for money (i.e., to satisfy the $\mathrm{Dd}^{s}=\mathrm{Dd}^{\mathrm{d}}$ equation of the mode1), $r^{91}$ must fall and via the term structure equations $r^{3}$ and $r^{10}$ fall as well. Allowing for a greater first-quarter response in Ds by replacing equation III. 3 of the model by equation 1 of Table II (which embodies a much quicker adjustment to equilibrium for a change in income) results in a set of impact multipliers embodying increases in interest rates (column 3).

Whether or not interest-rates rise or fall also depends on how the monetary authorities respond to a change in income. If we replace the base equation of the model by equation 3 of Table II which has the central bank responding with a one-quarter lag.to any changes in income, then the money supply will not be affected directly by the increased income. As one would expect, interest rates will rise (see column 7). 25 This is similar to the classroom experiment of shifting the IS curve without altering the IM curve. Quite the opposite extreme is characteristic of the impact multipliers in column 8 . The base equation for this experiment (equation 2, Table II) has the central bank increasing $B$ by 7.4 cents for every dollar increase in $Y$ with the result that interest rates fall considerably (compare columns 8 and 3 , the difference being that column 8 embodies a larger response of $B$ to $Y$ ). Traditional macro theory suggests

25 The money supply actually decreases in column 7 even though the base increases. This occurs because of the differing impact of $G$ on $\bar{C}_{t}$ and $C_{t} \cdot$ Notice that $\bar{C}_{t}$ increases by .49 million dollars and $B$ increases by .24 million dollars (the coefficient of $\bar{c}_{t}$ is .45 ) but that $c_{t}$ increases by .77 million thereby reducing bank reserves by .53 million (i.e., .77-.24) and forcing a 13-fold decrease in bank money $\left(i_{0} e_{.}, D_{s}=-6.9\right)$. With hindsight, it would have been more appropriate to specify the $\bar{C}_{t}$ equation in the same manner as $C_{t}$ in order that the shortrun responses would be more similar. In the steady state they respond very similarly (e.g., see column 2). 
that the increase in income for a given change in $G$ will be larger the more expansionary is monetary policy (i.e., the more the LM curve shifts to the right). This is confirmed: $\$ 121$ million, $\$ 109$ million and $\$ 95$ million are the figures for columns 8,1 , and 7 respectively. clearly, then, the results in Table III are very sensitive to the specification of the base equation. 26

Columns 3 to 6 trace out the effect of a $\$ 100$ million change in $G$ through several subperiods including the final equilibrium. While the model does converge to equilibrium the rate at which it does so is rather slow. By the end of the sixth quarter $Y$, for example, attains only $50 \%$ of its steady state value.

One of the disadvantages of a model in which the monetary base is endogenous is that one cannot investigate the behavior of the system in response to an exogenous change in the base. We circumvent this problem in the following manner. Included in the equation for the base are several exogenous variables that do not appear in any other equations $\left(e . g ., r^{\text {us }}\right)$. We change these exogenous variables in such a manner as to produce an increase in $B$ of $\$ 10$ million dollars. The immediate result will also be a $\$ 10$ million increase in reserves. Colums 9 and 10 present the impact and steady state multipliers for this experiment. After the initial exogenous change in $B$, there are, of course, some induced changes in B as the economy moves toward equilibrium. The results are interesting. While interest rates in the steady state are below their initial values, they are far above their low short-run levels in spite of the additional (induced) increases in the money supply.

${ }^{26}$ See footnote 21 for the reason we chose the III.5 specification for the model. 
This lends support to the Tucker hypothesis relating to the lag in monetary policy, i.e.,

In a linear model in which the behavioural equations have distributed lags and in which the money and product markets are cleared in every period, the interest rate, in performing its function of clearing the money market, will overshoot its new equilibrium as soon as the money supply changes... . If it overshoots far enough, it will cause both investment and income to overshoot, as well... . No matter how long the product demand lags, however, adjustment [to equilibrium] is very rapid if the moneydemand lag is comparatively long. [19, p. 447].

That the interest rate "overshoots" is obvious. In addition the adjustment to equilibrium is fast in the sense that the value of $Y$ in the first quarter is $50 \%$ of its final equilibrium value. Finally, the change in investment (not shown) in the first quarter is 2.45 while in final equilibrium the investment change is only 2.14 .

\section{Money Demand, Money Supply, m and v}

The last twelve rows of Table III summarize the dynamic interaction between money demand and money supply. Focussing on either columns 1 and 2 or 3 to 6 , it is evident that the result of an increase in an exogenous component of income, i.e., G, is an increase in the money supply multiplier. Furthermore, the steady state value for m exceeds the short-run value. This is due primarily to the continuous temporal decline in $c$ and the rise in $n$. Unlike the results of the elasticity exercise, both the impact and steady state values for $s$ are lower than the initial value. This results because the effect of rising interest rates is to decrease s. ${ }^{27}$ The specification for the Ds equation also matters considerably: comparing columns 2 and 1 , the long-run value for $s$ is

27. The elasticity of Ds (in equation III.3) with respect to $r^{10}$ is much higher in absolute value than the elasticity of Dd with respect to its interest rate, $r^{91}$ (i.e., -.67 vs -.113 ). 
greater than the impact value while the reverse is true for columns 6 and 3 . The long-run money multipliers reflect this, i.e., $m$ is greater in column 6 than in column 2. Even though the money supply multiplier increases over time, the relative contribution of $\mathrm{m}$ to changes in the money supply declines as the economy tends to equilibrium (5th row from bottom). In the first quarter, the multiplier accounts for over $50 \%$ of the increase in money (column 1 ). In equilibrium, the multiplier accounts for $15 \%$ (column 2) of the increased money supply, the remaining $85 \%$ stemming from an increase in $B^{\prime}$ (since $d \log M=$ $\left.\mathrm{d} \log \mathrm{m}+\mathrm{d} \log \mathrm{B}^{\prime}\right) .^{28}$

Turning to the behavior of velocity, the result of an exogenous increase in the income component, $G$, is a considerable increase in $v$ in the first quarter (column 1) and a much smaller steady-state increase (column 2). This result too is somewhat different from that obtained from the elasticity exercise in the first part of this section where velocity fell in the long run. Again the difference in results stems in large measure from the fact that interest rates rise in the long run (column 2) and this increases velocity. Regardless of the specification of the base equation or the equation for $D s$, the effect of an exogenous change in some income component is to increase velocity in both the short run and the steady state (see columns 1 through 8 ). As a result, then, of an exogenous increase in $G$ the public allocates its money assets in a manner that enables a given monetary base to support a greater money supply (i.e., m increases), and in addition the public economizes on money so that a greater

${ }^{28}$ Incidentally, in the analysis of the contributions of the "proximate determinants" to the money supply (referred to in fn. 6), the multiplier accounts for $15 \%$ of the change in the money supply over the 1955-1965 period. 
level of income can be maintained with a given money supply (i.e., $v$ increases). ${ }^{29}$

The results change considerably when equilibrium is disturbed by an exogenous change in the monetary base (columns 9 and 10). In particular the money multiplier behaves in a manner that accentuates the change in the base. For both the impact and steady state situation the money supply multiplier records its highest value. In the steady state, for example, the increase in the multiplier accounts for $32 \%$ of the change in the money supply. In large measure this is due to the decrease in interest rates in the steady state and the accompanying increase in $s$. This is the only case in Table III where $s$ registers an increase. Along with the multiplier having its largest increases, velocity experiences its only decreases in these two columns. Furthermore the long-run change in velocity is slightly larger (but still negative) than the short-run change whereas the opposite was true for the other two steady state values (compare columns 2 with 1, 6 with 3 , and 10 with 9). There appears to be a clear tendency for velocity and the multiplier to move in offsetting directions. This is especially evident in columns 7 and 9 where the \% changes in m are of different sign from those in $v$. Even in the 3 other columns displaying impact multipliers where the changes in both $\mathrm{m}$ and $\mathrm{v}$ are positive, the greater the $\%$ change in $\mathrm{m}$ the less is the $\%$ increase in $\mathrm{v}$.

This leads us to the last two rows of the table which present values for $\mathrm{vm}$ and the percentage changes in vm. Note that the latter is the sum of the percentage changes in $\mathrm{m}$ and in $\mathrm{v}$. In all cases where equilibrium is disturbed by a change in an exogenous income component both $\mathrm{m}$ and $\mathrm{v}$ increase so that the

${ }^{29}$ There is one exception to this statement. In column 7 where the base responds to lagged income, $Y_{t-1}$, rather than to $Y_{t}$ the money multiplier decreases in response to an increase in G. (See footnote 25 for an explanation of why the base increases a wee bit i.e., .24). However, the velocity records its largest increase here--nearly $3 / 4$ of $1 \%$. If we may extrapolate these results they suggest that the impact multiplier will be lowest and velocity highest when an exogenous increase in income is not accompanied by any change in the monetary base. 
percentage increase in the income velocity of the base (i.e., in mv) is greater than the income velocity of money, $v$ (except for the impact multipliers in column 7). In general, the greater the response of the base the greater is the product mv relative to $\mathrm{v}$. This is especially true where the exogenous change occurs in the monetary sector. In this case the movements in $\mathrm{m}$ and $\mathrm{v}$ largely offset each other leaving mv relatively unchanged. While we have not tested in any direct functional manner for the stability of $\mathrm{mv}$ or $\mathrm{v}$, it is clear from our limited experiments that as a number, mv has a smaller variance than does $v$. In other words, movements in $v$ (looking at percentage changes) tend to be negatively correlated with movements in $\mathrm{m}$.

Given, therefore, the direct relationship between $Y$ and $m$ and the tendency for $m$ to be positively related to changes in $M$ (due, in part, to the effect of $M$ on interest rates), it is not surprising that direct estimation of the behavior of the money supply multiplier yields positive and negative coefficients for $\mathrm{Y}_{t}$ and $\mathrm{r}_{\mathrm{t}}^{10}$ respectively:

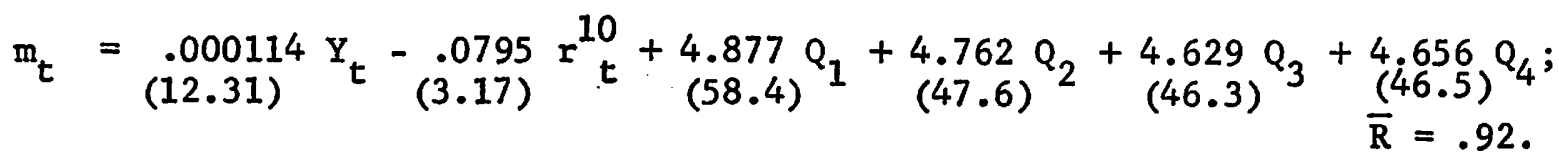

But, like the elasticity analysis in the first part of this section, direct estimation of the determinants of $m$ conceals most of the complex interaction between m and $Y$ and $B$ that the model reveals.

The Bank Act of 1967

Under the provisions of the 1967 Bank Act ${ }^{30}$ the money multiplier formulation II.9 will have to be altered somewhat. Specifically, the first $r$ in the

${ }^{30}$ In terms of our analysis, the principal revisions relate to the a) removal of the interest-rate ceiling on the asset side of the banks and $b$ ) adoption of a dual legal reserve ratio- $4 \%$ against $\mathrm{Ds}$ and $\mathrm{Dn}$, and $12 \%$ against Dd and $\mathrm{Dg}$. Interestingly enough just as Canada is, in the adoption of the dual rate, moving more towards the U.S. system, the U.S. is moving toward our system: a lagged reserve-settlement scheme was recently introduced in the U.S. The grass always looks greener.... 
denominator will equal .12 while the remaining two will equal .04 (assuming that Canadian banks will continue to be "loaned up"). As it turns out, the deposits which have the highest income elasticities (i.e., Ds and Dn) are now subject to lower reserve requirements than are demand deposits. In addition the chartered banks, now freed from their interest-rate restrictions, can compete more actively for these deposits. Extrapolating our results, then, it would appear that the upward trend in the money supply multiplier will likely be more pronounced in the future.

In the model we assumed that the chartered banks satisfied, at existing rates, all demands for Ds and Dn (equations III.10 and III.11) and that demand deposits bore the brunt of ensuring that $D^{s}$ equalled $D^{d}$. This assumption is less realistic now that the banks have greater freedom in adjusting the rates paid for Ds and Dn and in this way can satisfy the requirement that demand and supply of Canadian dollar deposit liabilities are equalized. Indeed, even if banks are fully "loaned up", a given quantity of reserves can imply a varying supply of total deposit liabilities depending on the composition of these liabilities. Under the Bank Act provisions, therefore, the chartered banks will play a far greater role in the Canadian money supply process than they have in the past. In this sense, they are becoming more like their American counterparts. One result of this should be to increase substantially the volatility of the money supply multiplier.

Some evidence to date already points in this direction. Since by far the greater proportion of Canadian dollar deposits are either Ds or Dn and, therefore, subject to the $4 \%$ reserve requirement, the immediate result of the Bank Act revisions was a sharp decrease in the overall required reserve ratio--from $8 \%$ to approximately $61 / 2 \%$ and a correspondingly sharp increase in the money supply multiplier. From June 1967 (when the reserve requirement changes began to be 
implemented) to June 1968 the money supply multiplier increased by 15\%. Over this same period the increase in the money supply was $14 \%$, i.e., the monetary base fell by $1 \%$. On the issue of the likelihood of their being greater variability in $\mathrm{m}$ in the future we note only that in the year prior to the introduction of the Bank Act, a) there was no variability in the required reserve ratio and b) the range of actual monthly reserve ratios to the average actual reserve ratio was approximately 4/5 of 1\%. From June 1968 to June 1969, however, the range of both required and actual reserve ratios divided by their respective average values was approximately $41 / 2 \%$. As interesting as the relation among $B$, $\mathrm{m}$, and $\mathrm{v}$ may have been in the past it promises to be more interesting and more important in the future.

\section{Conclusion}

The purpose of this paper was to construct a model of the money supply process in Canada and in particular to focus on the interaction between money supply and money demand. One conclusion that we are able to draw is that there is an inverse relationship between $v$ and $m$ which stems largely from the differing impact on $v$ and $m$ of a change in interest rates: a rise in interest rate increases velocity and, because of the interest insensitivity of currency relative to other types of money which increases the currency ratio, lowers the money supply multiplier. An important implication of this behavior is that movements in the product mv are, numerically, more stable than movements in velocity, i.e., the interaction between $m$ and $v$ is such that the relationship between $M$ and $Y$ is more variable than that between $B$ and $Y$.

A second major conclusion is that the money supply multiplier contributes significantly to changes in the money stock--anywhere from $13 \%$ to $30 \%$ in 1 ongrun equilibrium. Since we assumed that the chartered-bank reserve ratio remained 
constant, all the change in m results from the public's altering the ratios in which it holds the various components of money. To a significant degree, therefore, the supply of money is not independent of the demand for money. And this will be all the more true under the provisions of the new Bank Act.

A third and very important implication of the model relates to the extent to which the base itself is an endogenous variable. The several equations included for the base indicate that much of the movement in B can be quite adequately represented as being determined by the announced goals of monetary policy. To the extent that $m$ and $v$ affect the various monetary policy targets, this is further evidence that the supply of money is not independent of the demand for money. But even granted the assumption that the base equation is temporally stable, the fact that many of the variables in the base equations are exogenous and that over $10 \%$ of the variance is left unexplained as well as the fact that $\mathrm{m}$ and $v$ impinge only partially on the values of the target variables suggests that this need not do violence to the quantity theory assumption that the supply of money be independent of the demand for money. Yet there is one case where this is definitely not true. In the steady state, changes in the demand for currency by the Canadian public are fully offset by changes in the base. Therefore, each dollar increase in currency will increase the supply of money by an equivalent amount. Essentially, then, the Bank of Canada over this period has aimed for a given level of "bank money" and permitted the level of currency outside banks to settle at any level desired by the public, i.e., the level of bank reserves, and not the monetary base, has been the monetary policy instrument in Canada over the period 1955-1965. 
APPENDIX A

List of Variables

(Alphabetized)

Unless otherwise stated all variables are in current dollars, and are not adjusted for seasonality. In addition, flow variables are at quarterly rates. All monetary data are month-end values. An interest rate of $5 \%$ is coded as 5.00 .

A - average maturity of the publicly held federal government debt (in year.

ARP - average repayment period (in months) on retail paper

B - high-powered money, i.e., bank reserves plus currency (excluding coin) outside banks

B' - high-powered money less reserves required to support federal government deposits at the chartered banks

$B C D$ - difference between month-end and average-of-Wednesdays chartered-bank deposits at the Bank of Canada

C - currency outside banks (excludes coin), month end

$\bar{c} \quad$ - currency outside banks average-of-Wednesdays for the last month of each quarter (excludes coin)

Cd - durable consumption expenditures

Cn - consumer expenditures on non-durables and services

D - Canadian dollar deposit liabilities (the sum of Dd, Ds, Dn and Dg)

Dd - demand deposits (includes demand deposits of the banks (primarily foreign banks, provincial government deposits, and is gross of

Dg - federal government deposits with the chartered banks

Dn - non-personal term and notice deposits

Ds - personal saving deposits

DIURN - turnover ratio of denand deposits (at annual rates) defined as the ratio of cheques cashed to an average level of deposits

G - government expenditures on goods and services, plus other variables such as Exports to complete the income identity

HS - housing starts (in thousands of units) multiplied by residential construction price index $(1948=1.00)$

$r^{3}$ - rate on government bonds with less than 3 years to maturity

$r^{5}$ - rate on five-year trust company certificates

$r^{10}$ - long-term government-bond rate (greater than ten years to maturity)

$\mathrm{r}^{91}$ - 91-day treasury bill rate

$r^{m} \quad$ - average of conventional mortgage and NHA $\operatorname{maximum}_{7}$ rate

$r^{n} \quad$ normal rate variable, defined as $r^{10}-\frac{1}{8} \sum_{i=0}^{7} r_{t-i}^{10}$, i.e., the current rate minus an 8 quarter average 


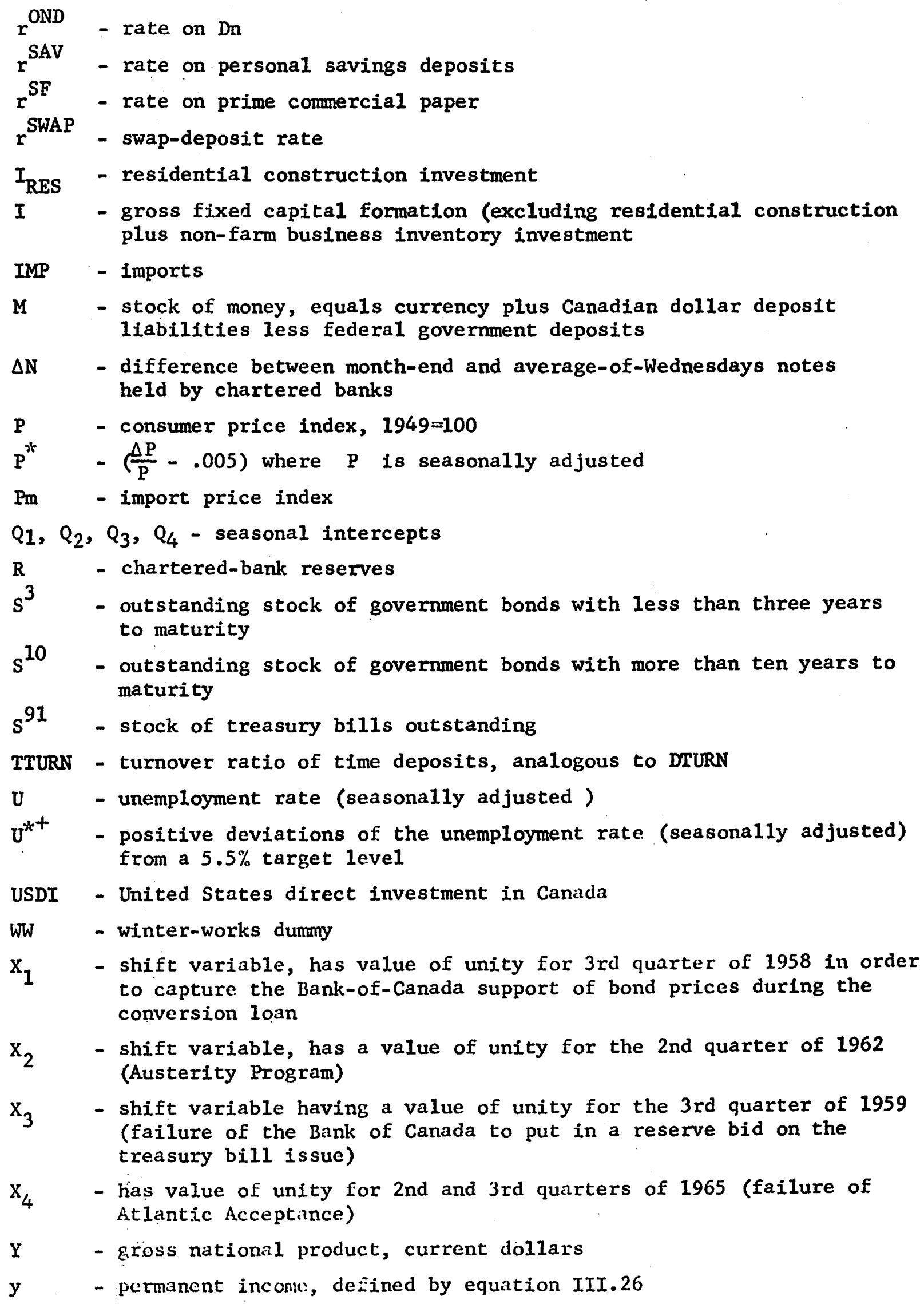




\section{APPENDIX B \\ Notes on the Rea1-Sector Equations}

1. The real-sector equations are stimated in current rather than constant dollars, following one variant of the Goldfeld [6] model. The linkages between the monetary and the real sector are restricted primarily to interest-rate effects although a variant of a real-balance effect is included in the equation for consumer durables.

2. The two-equation submodel explaining residential construction was adapted from L. B. Smith [18]. The only change was to convert housing starts to reflect changes in the price level. This was done by multiplying them by a construction price index $(1949=1.00)$.

3. The consumer durables equation was modelled after the Goldfeld specification $[6, p .135]$. The ARP ${ }_{t}$ variable appeared previously in Shapiro $[16$, p. 137]

4. The use of unemployment as a capacity influence on imports is an adaptation of the GNP gap formulation employment by T. R. Robinson [15] . Naturally, the gap variable also "works".

5. The formulation for permanent income is from the Bank of Canada. 


\section{Literature Cited}

1. Bank of Canada. Evidence of the Governor before the Royal Commission on Banking and Finance. Ottawa: Bank of Canada, 1964.

2. Brunner, Karl and A. H. Meltzer. 'Liquidity Traps for Money, Bank Credit, and Interest Rates," Journal of Political Economy, vol. 76 (January/ February, 1968), pp. 1-38.

3. Canadian Bankers' Association. Submissions to the Royal Commission on Banking and Finance, 1963.

4. Cagan, Phillip. Determinants and Effects of Changes in the Stock of Money 1875-1960. New York: National Bureau of Economic Research, 1965.

5. Fand, David I. and John E. Tower. "An Analysis of the Money Supply Process in Canada," The Canadian Journal of Economics, vo1 I (May, 1968), pp. $380-400$.

6. Goldfeld, S. M. Commercial Bank Behavior and Economic Activity. Amsterdam: North Holland, 1966.

7. Heller, H. R. "The Demand for Money: The Evidence from the Short-Run Data," Quarterly Journal of Economics, vol. LXXIX (May, 1965, pp. 291-303.

8. Helliwe11, John F., l.awrence H. Officer, Harold T. Shapiro, and Ian A. Stewart. The Structure of RDXI, Bank of Canada Staff Research Studies No. 3. Ottawa, 1969.

9. Johnson, H. G. and J.W.I. Winder. Lags in the Etfects of Monetary Policy in Canada, working paper prepared for the Royal Commission on Banking and Finance. Ottawa: Queen's Printer, 1962.

10. Keliy, A. K. The Money Multiplier and the Canadian Money Supply. Unpublished Ph.D. dissertation (Department of Economics: University of Western Ontario), 1968.

11. Jindbeck, Assar. A Study in Monetary Analysis. Stockholm: Almqvist and Wiksell, 1963.

12. Miles, Pelcr. Asscts and Liabilities of Chartered Banks: An' Econometric Analysis. Unpublished Ph.D. dissertation (Department of Economics and Political Science, McGill University), 1968.

13. - "Sone Empirical Evidence on the Influence of Interest-Rate Expectations on Financial Behaviour," Paper read to annual meetings of Canadian Economics Association. Calgary (June, 1968).

14. Reuber, G. I. "ihe objectives of Canadian Monetary Policy 1949-61: Empirical Tracie-Ofts and the Reaction Functions of the Authorities," Journal of Political Econony, vol. LXXII (April, 1964), pp. 109-132. 
15. Robinson, T. R. "Canada's Imports and Economic Stability," The Canadian Journal of Economics, vol. I (May, 1968).

16. Shapiro, 11. T. The Canadian Monetary Sector: An Jimpirlcal Anilysis. Unpulilished ph.D. dissertation (Department of ficonomics, princeton University), 1964.

17. Shearer, Ronald. The Foreign Currency Business of Canadian Chartered Banks," Canadian Journal of Economics and Political Science, XXXI (August, 1965), pp. 341-48.

18. Smith, L. B. "A Model of the Canadian Housing and Mortgage Market," (mimeo), 1968.

19. Tucker, D. P. "Income Adjustment to Money-Supply Changes," American Economic Review, LVI (June, 1966), pp. 433-49.

20. Wood, John H. "A Model of: Tederal Reserve Behavior." As reprinted in Monetary Process and Policy: A Symposium, ed. George Horwich. Homewood, I11.: Richard D. Irwin, 1967, pp. 135-166. 